\title{
Urban Participatory Design through Technology: Birloki System, a Network of Interactive Interfaces
}

\author{
Juan Sádaba ${ }^{1}$ and Sara Lenzi ${ }^{2}$ \\ 1. Nerei Emotional Intelligent S.A., Singapore 068574, Singapore \\ 2. Lorelei Sound Strategies, Pte. Ltd, Singapore 079903, Singapore
}

\begin{abstract}
By 2050, the UN (United Nations) expects the number of city dwellers to reach 6.3 billion and the balance of humans in cities to rise to about $70 \%$. At the same time, the vertiginous development of information technologies opens up a new world of possibilities to improve the quality of life of citizens. Our research is focused on the possibilities of work in the urban design and public realm that these new information technologies are starting to open up. Based on the concept of urban acupuncture and on the so called u-pad methodology, we create a network of interactive and adaptive points that put together the three fields of technology, design and emotion to create information and activation points on the city. The prototypes of the Birloki system BL1-r01-tp01 and BL1-r01-tp02 are already built and being tested to be operative in the streets of Bilbao (Spain) as a first testbed. The project deploys seven Level 1 (BL1) and 10-12 Level 2 Birloki points over the Old Town (the medieval centre of the modern city (in Spanish: Casco Viejo)), focusing on residents and visitors. They will convey and collect information and data and interact with the users, utilizing combinability, interactive devices, augmented reality, i-beacon technology and others. These data can be collected and re-input in the flow to improve the system and therefore the experience of the user/citizen.
\end{abstract}

Key words: Interactive furniture, smart cities, interaction, urban design.

\section{Introduction}

By 2050, 6 billions of out of the 10 billions' world population will live in cities (Fig. 1). This new urban environment will also be the centre of the world economy. As a 2012 study by MacKinsey [1] points out, by 2050 the 600 biggest cities in the world will account for the $60 \%$ of global GDP (gross domestic product). On the other hand, cities will also be doomed to produce the highest percentage of the $\mathrm{CO}_{2}$ emissions and therefore highly contribute to the climate changes that are already on their way. At the moment, cities contribute to the $70 \%$ of the carbon emissions of the planet [2]. In this scenario, the urban environment will progressively absorb the natural one, creating a continuous landscape that will include urban areas and green areas seamlessly.

These figures have put a pressure on the world

Corresponding author: Juan Sádaba, chief innovation officer, research fields: urban design, interactive design, new cities, territorial planning, mobility and product design. governments to research and develop scenarios for smarter cities that will be able to face the challenges involved in this unprecedented change in human history.

In the words of Carlo Ratti, from the MIT (Massachusetts Institute of Technology) Senseable Cities Lab: "Four numbers characterize the importance of cities: $2-5-75-80$. Globally, cities are only $2 \%$ of the planet's surface, but are home to $50 \%$ of the population and are responsible for $75 \%$ of energy consumption and $80 \%$ of carbon dioxide emissions. We do not need to wait until 2050, we have to work on cities today" [3].

The currently envisaged state-of-the-art solutions are built on three distinct and separate approaches:

- digital, IT (information technology) based solutions;

- architecture and infrastructure planning and building solutions;

- policies of citizens' inclusion in the decision-making process, that covers a wide range of 


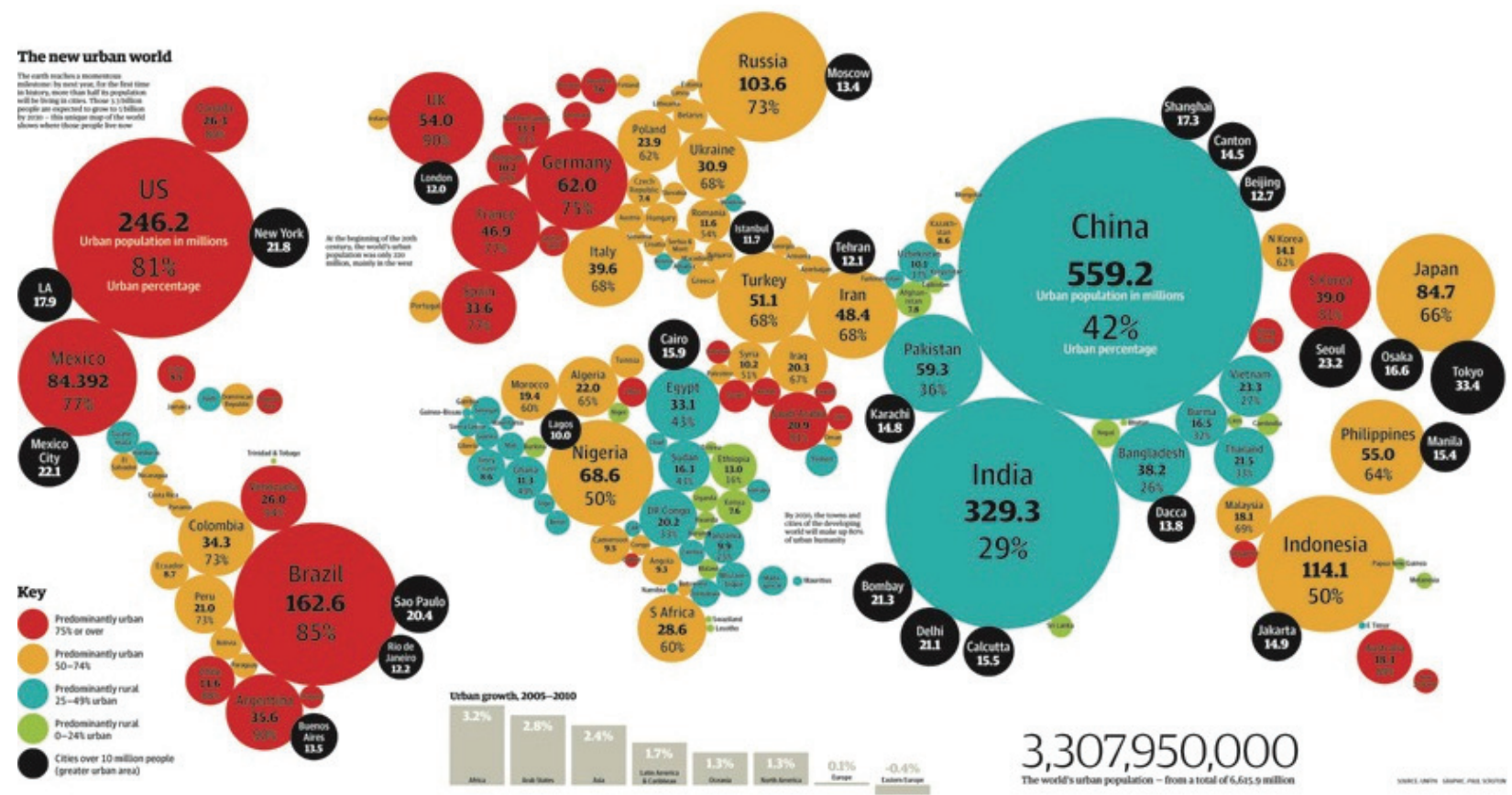

Fig. 1 Percentage of urban population [4].

Source: image "Urban World" by the Guardian.
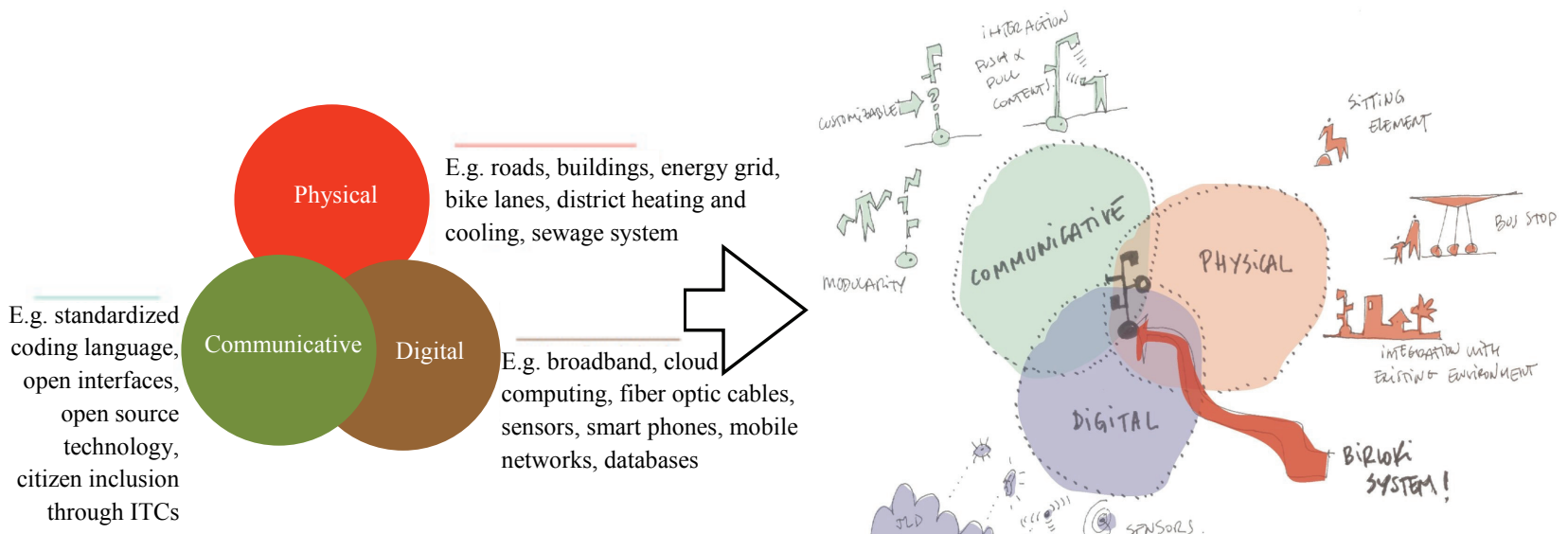

吕

Fig. 2 Components of urban interaction.

Source: the image is inspired by the CCC (Copenhagen Cleantech Cluster) 2012, including the definition of the three components of the urban interaction: physical, communicative and digital.

initiatives from bottom to up, interactive IT solutions, immersive and enhanced experiences in the urban environment.

Our proposal's current industry landscape therefore includes three distinct industries and markets (Fig. 2):

- urban design;

- information and communication technologies;

- emotional and experiential design.

\section{Interactive Urban Furniture: The Network, Urban Acupuncture}

In this varied and rapidly evolving scenario, we propose an integrated solution that combines urban design, IT solutions and emotional design. The underlying concept of this solution is "urban acupuncture".

Urban acupuncture is a term that relates directly to 
Asian culture and to a holistic point of view that engages perfectly with our vision of the future. These two words have already appeared timidly to describe punctual little actions to solve urban problems with a bottom-up approach. But acupuncture infers a much more comprehensive conception of the world and therefore of urban design. Acupuncture understands the body (the city) as a whole, as a balanced network of streams and flows, each of them with a specific sense and function. In this sense, we go a little further than the concept used by the politician and urban planner Jaime Lerner [5].

Urban design analyzes the diverse flows of energy of the city (mobility, power supply, social connections...) and identifies possible lacks of energy, points where the flow is broken or can be enhanced (by strengthening or lowering it).

We have designed interactive, user friendly and ergonomic needles, creating a network of points that enables creating a more vivid, liveable and efficient city.

When the "needles" are on and connected, the streams of information such as efficiency, transport and emotions flow freely and balancing the seamless connectivity and interactivity of the smart city of the future.

In the last few years, since the smart city concept appeared in our lives, we have been looking for a city that reveals intelligent but also gives the citizen the opportunity to deal with the city in a closer range. The search for the optimization of resources and the efficiency and control of facilities, made us forget many times the day-to-day life of the citizens. There are things in the city that are as important as these and that can be unveiled only from the street point of view. We introduce a new concept (Fig. 3) to tackle the urban space solutions in the city. Urban acupuncture is an innovative approach that blends together urban hardware and urban software to provide a plug and play interactive way to address our cities. Birloki system offers a new way of thinking urban furniture. Interaction with our own personal devices has become familiar and we expect the same level of real-time personalization with the sphere of public objects on the streets. Birloki system has been awarded at the 2010 International Concept Design B_Awards. In 2012,

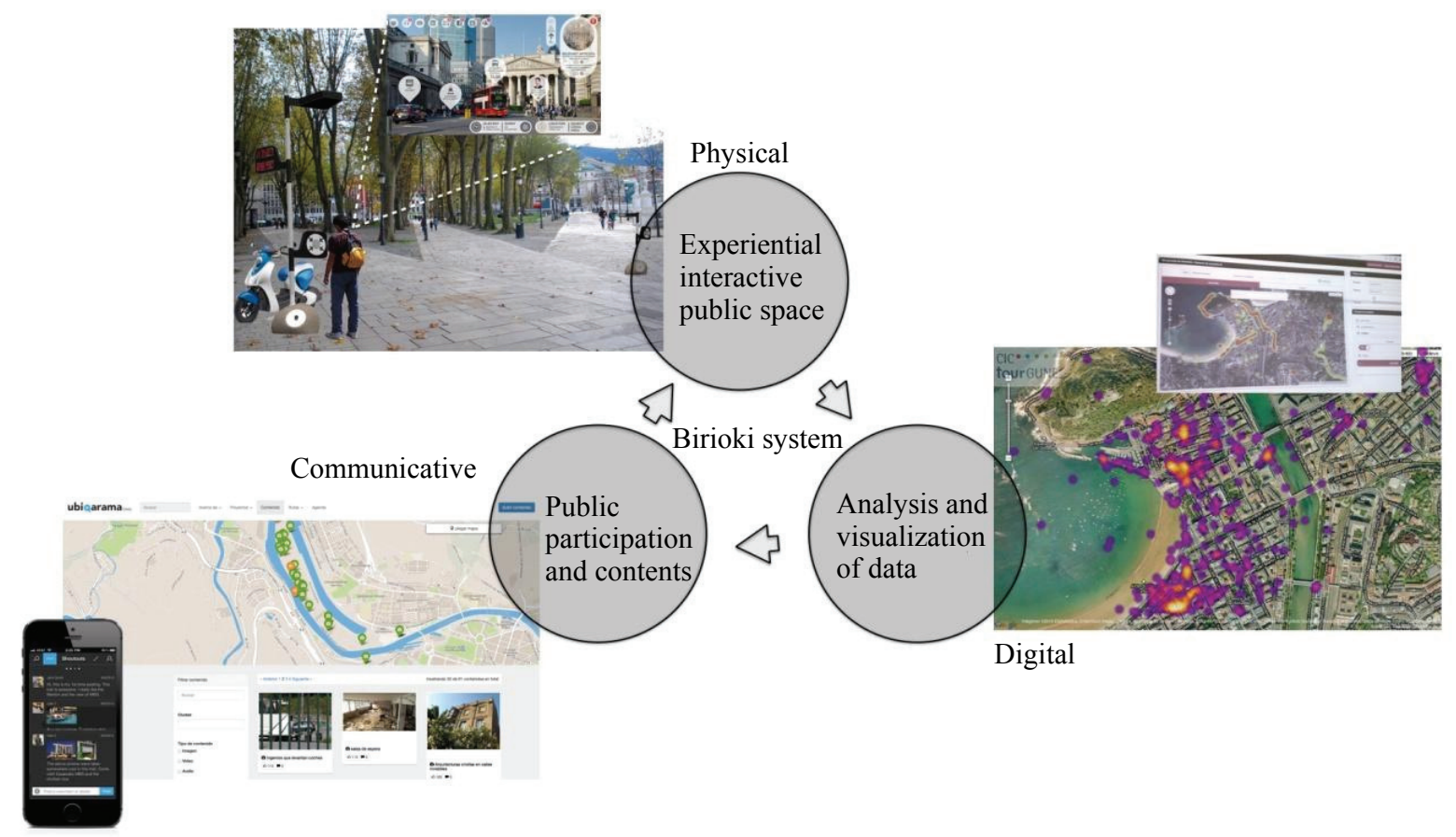

Fig. 3 The Birloki system lies at the centre of the communicative-physical-digital components of the future city. 
it was selected as finalist innovative initiative in the Smart City World Congress Awards and again in 2014 nominee for the Media Architecture Biennale Awards.

\section{Implementation: The U-Pad Method}

The confluence of this three pillars over the urban realm will most probably give birth to a new or, at lest, renewed urban science. In that case, it feels utterly important to develop a valid scientific method that can provide both a theoretical and practical support, scalable in any case. Based on this three legs, the digital, the communicative and the physical limbs (as defined before: urban design, IT, emotional and experiential design), we defined what is called the u-pad method. The u-pad method is based on the pad (pleasure, arousal, dominance) framework for describing and measuring individual differences in temperament [6].

It is also key and necessarily remarkable the fact that this method rises to tackle the problem of urban design and smart cities' issue from a mostly bottom-up perspective as opposite to the usual top-down approach of the big corporations, as we have known it so far.

The u-pad method establishes a circular system in which each of the aspects nurtures and gets also fed by the other two stages of the cycle, enabling a continuous feedback in order to optimize the system. We might start from a analog or digital collection of contents and public participation data, via workshops or open city data Apps that allow people to add information on top of those proposed by the municipality or the manager of the space itself. Once these data are incorporated to the system database and into the digital repository, they flow into the network of points over the city, where they will be taken by the users, who can also add other kinds of data. This way, the Birloki points act as city interfaces that communicate personally with both visitors or residents. The way these points create immersive and interactive experience is by means of technology, ad it adapts to new technological possibilities as they appear, on the basis that we created a modular and adaptive object/device: augmented reality Apps that identify the object or spots from the elements, iBeacon Bluetooth based technologies, etc. These two legs, the communicative and the physical aim to improve the participatory possibilities of the citizens.

The third part of the flow is the data collection and analysis. Part of it is open and consulted by anyone. Some other data belong to the city analysis and the municipality managers. The u-pad method puts the stress on participation and the human side of the smart cities and therefore we also collect "subjective" mood data through moodboards located at the Birloki points themselves and on the Apps. Only architecture that considers human scale and interaction can be considered good architecture [7]. Once the data are in the flow and analyzed, they feedback the system, allowing it to optimize. That is why we developed a resilient and adaptive system for the physical side: the Birloki.

\section{Birloki System: Urban Space Activator}

The core of the proposed solution is the interactive outdoor piece of furniture "Birloki" (Fig. 4). It is a highly flexible, adaptable and fully customizable interface between the city and the citizens. The system consists on a simple base element that works as a street connector onto which different functional elements are plugged. The concept of the solution is similar to the "Lego": It consists of interlocking parts that can be connected, assembled and re-assembled in many ways.

The composition of each Birloki can be changed and adapted regularly and seamlessly (Fig. 5), following the metamorphosis of the cityscape and the needs of the stakeholders (governments, agencies, citizens). The urban acupuncture healing process relies on the potential of an endless open recombination of the elements.

It consists of a modular system of plug and play devices that can be used independentlyto activate public spaces with interchangeable plugs. It is a simple base 

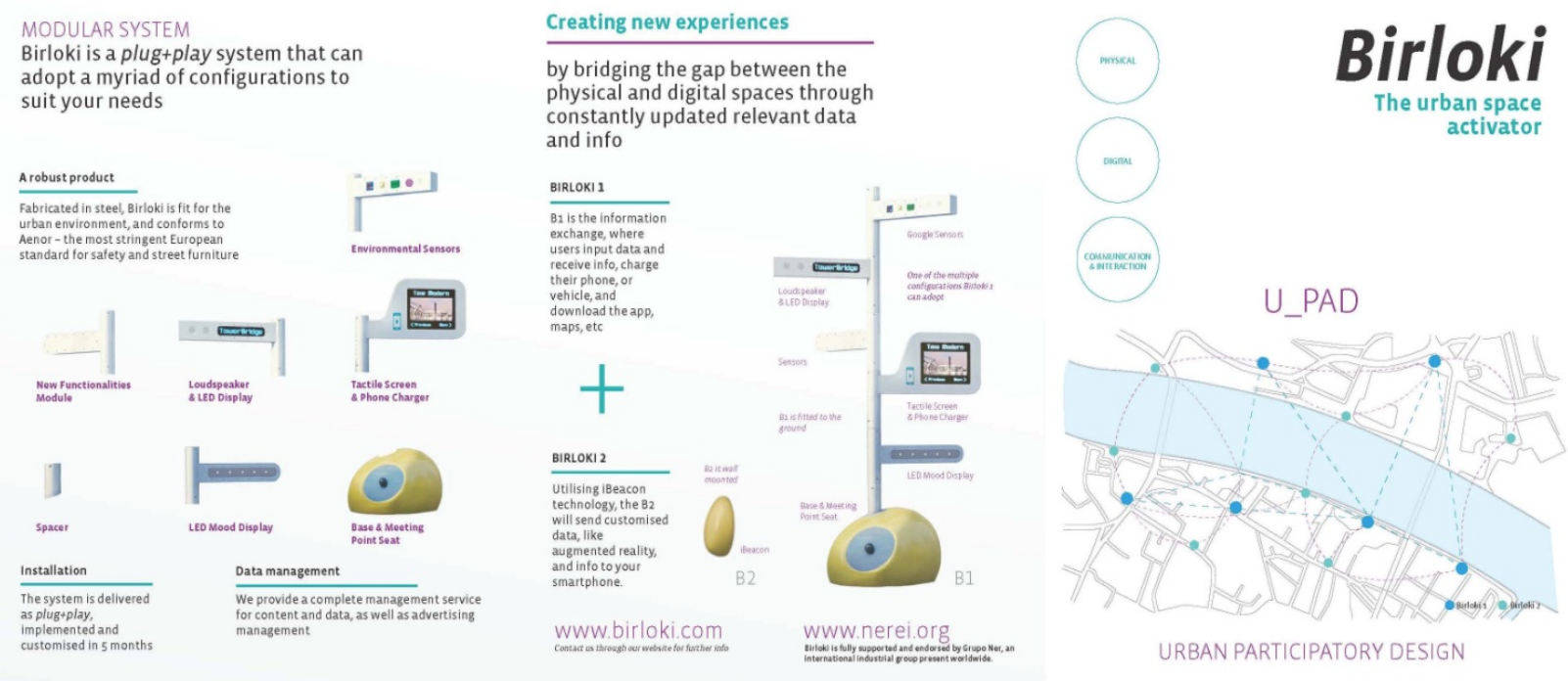

Fig. 4 The Birloki modular system and the u-pad approach to urban space.
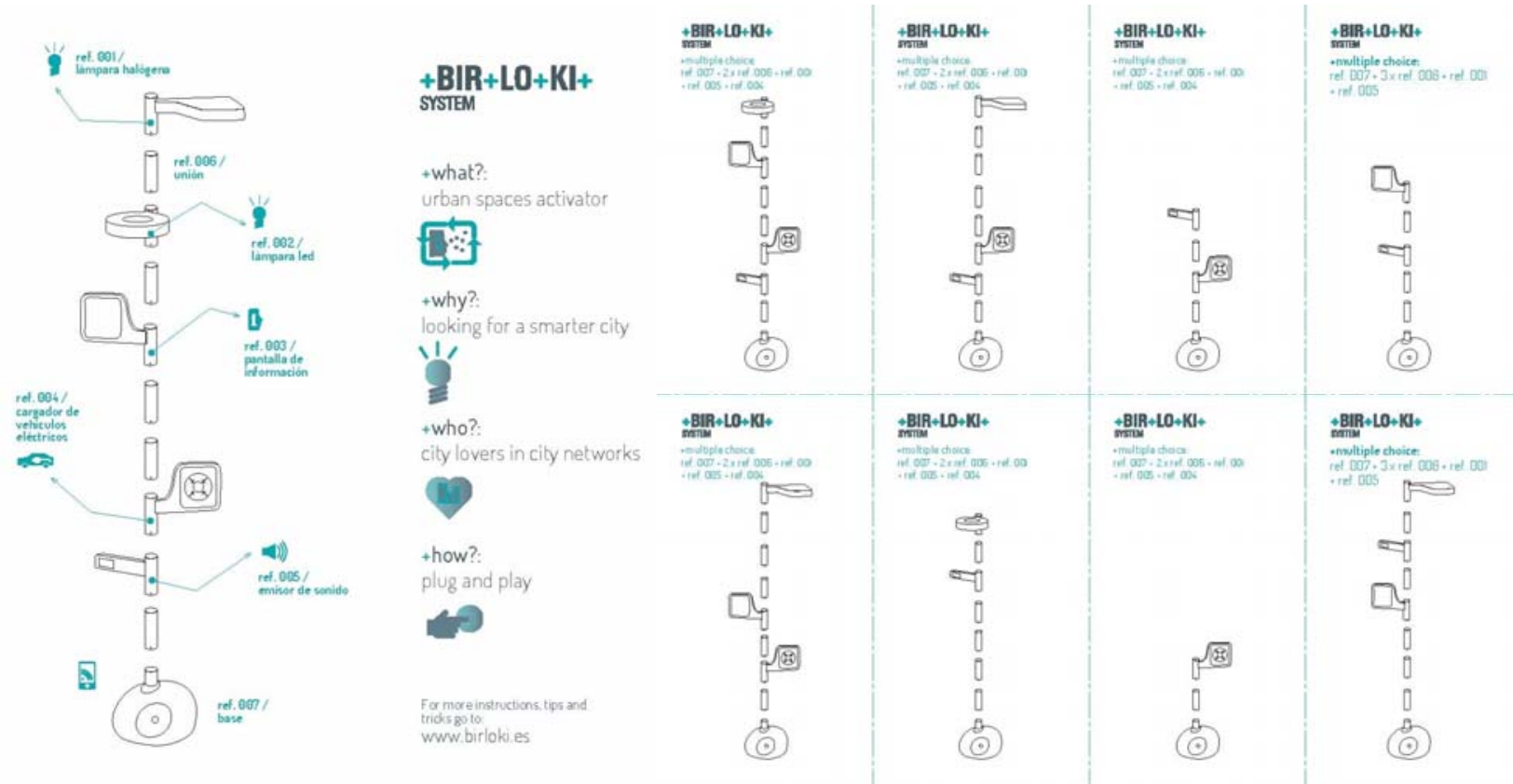

Fig. 5 The Birloki modular system, detail of the product.

element that works as a street connector onto which we can plug the different functional elements. Over the base element, you have the possibility of making your own, fully customizable composition. Up to the maximum height of $4 \mathrm{~m}$, you make your own combination with the different components combined and spacers between them when wanted, up to the desired height [8].

During the development process, we have been testing different components to enable diverse performances according to the needs of the city in each slot of time and specific space. However, the possibilities are infinite and there is the root and key of the project, that grows and evolves with the city itself.

Basically, it consists of a base element that provides a power point connected to the city facilities and a data connection. This connection can also be done through wifi $3 \mathrm{G}$ or $4 \mathrm{G}$. Inside the base, we install the electric panel and the central unit, that will talk both to the functional elements in the limbs of the Birloki and to 
the network. Mechanically, there is a simple fast connection that permits the different parts of the Birloki to be placed rapidly and with no technical problems, so that they can be readapted fast as it is required by the circumstances. The approximate diameter of the base is $600 \sim 700 \mathrm{~cm}$, with a height of $40 \sim 45 \mathrm{~cm}$ to perform as a sitting element and each of the units carrying the funcional elements has a height of $40 \mathrm{~cm}$. The combination of them has been calculated to a maximum height of $4 \mathrm{~m}$, as previously stated, which is a standard value for urban lamps. It has been developed, studied and calculated to comply legally with all the outdoor antivandalic, sustainability and performances requirements.

To complement the performance of the system so far presented, we developed an additional layer of elements, which was defined as Level 2 and would improve the experience of the user on the city by creating much more interactive and interesting routes. As seen in Fig. 6, these Level 2 Birloki points use iBeacon technology to push information onto the user's App and guarantee a better experience and understanding of the spaces you walk through.

\section{Prototyping}

Birloki system has different parts and components (Fig. 7), starting from the mechanical side and being complimented by the software, the hardware and a study of the correct experience of the user (UX/UI). The challenge is interesting, because it has not only to work as a finished prototype, but also runs properly when new functionalities are inserted and the combination reassembled. The physical and mechanical parts are manufactured in steel (Fig. 8a) and fiberglass ( the base) (Fig. 8b).

\section{Bilbao Testbed}

As a urban testbed, as a "urban prototype", the Birloki system will be deployed on the streets of Bilbao. This action will provide the research team with high value data on the performances of the elements and also, even more interesting, the real interaction of people with the network. We will be able to monitor a human pulse of the city and parametrize the flows of movement and mood variations of the visitors relating them to specific real meeting points. “... Project planners and urban designers assume they can create a promenade simply by mapping one in where they want it, then having it built. But a promenade needs promenaders" [9].

The Bilbao Municipality, enabling a bottom-up PPP (private public partnership) deal and being really supportive with their own innovative people and brave about being an avant-garde city as for participatory methods, is going to test the u-pad method and Birloki points over the Old Town (in Spanish: Casco Viejo).

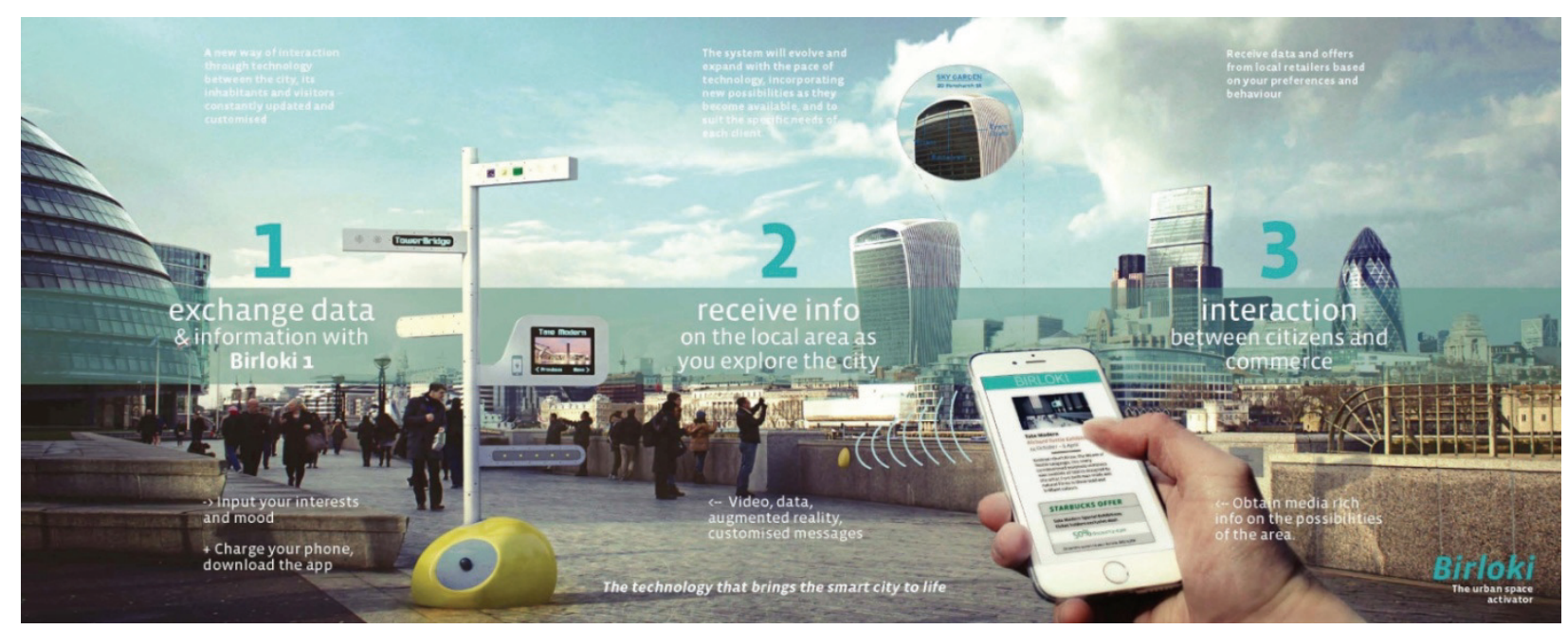

Fig. 6 The two levels of the birloki system: the system and the iBeacons + Apps network. 

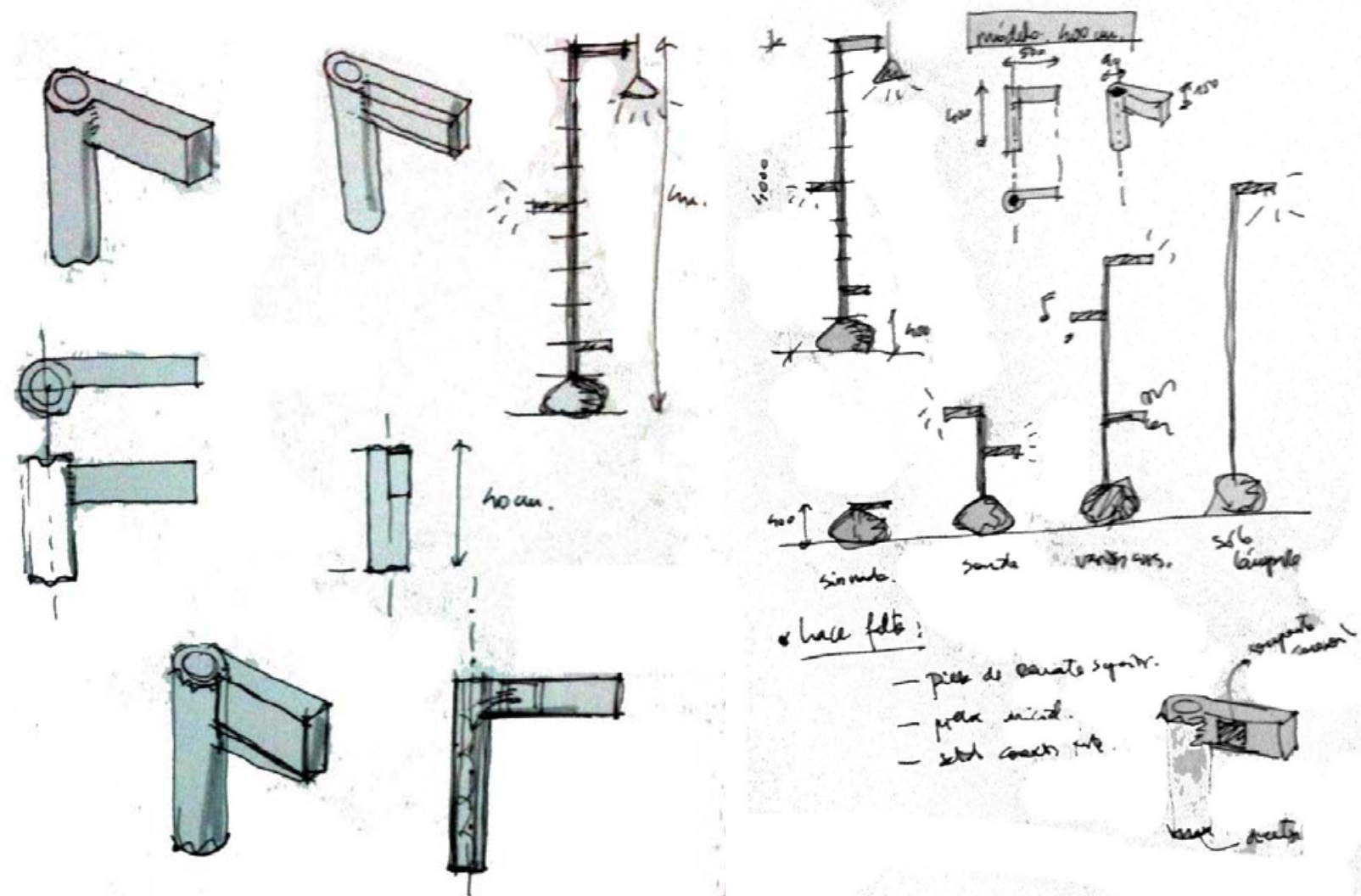

Fig. 7 Different parts and components of the Birloki system, preliminary sketches.

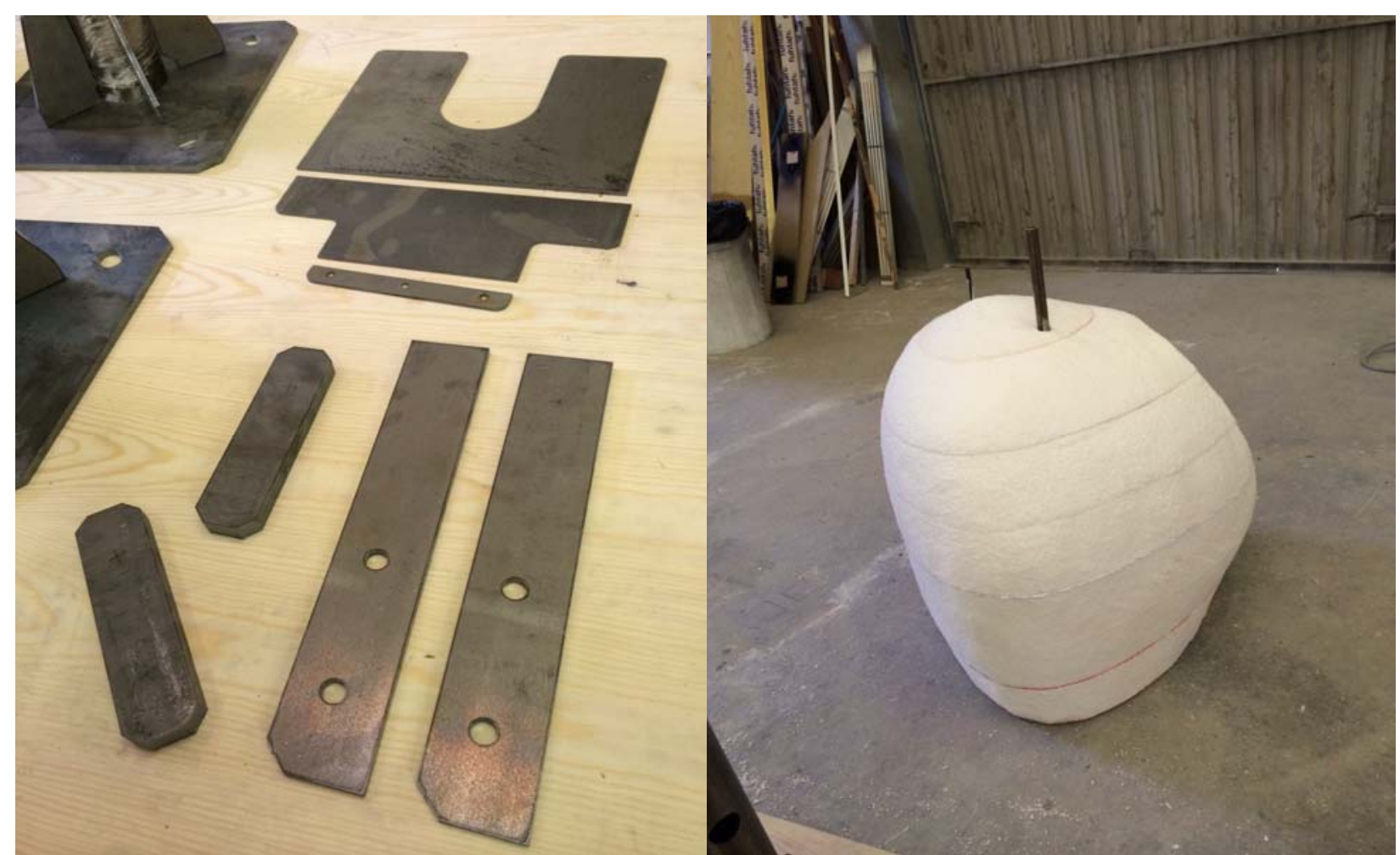

(a) 


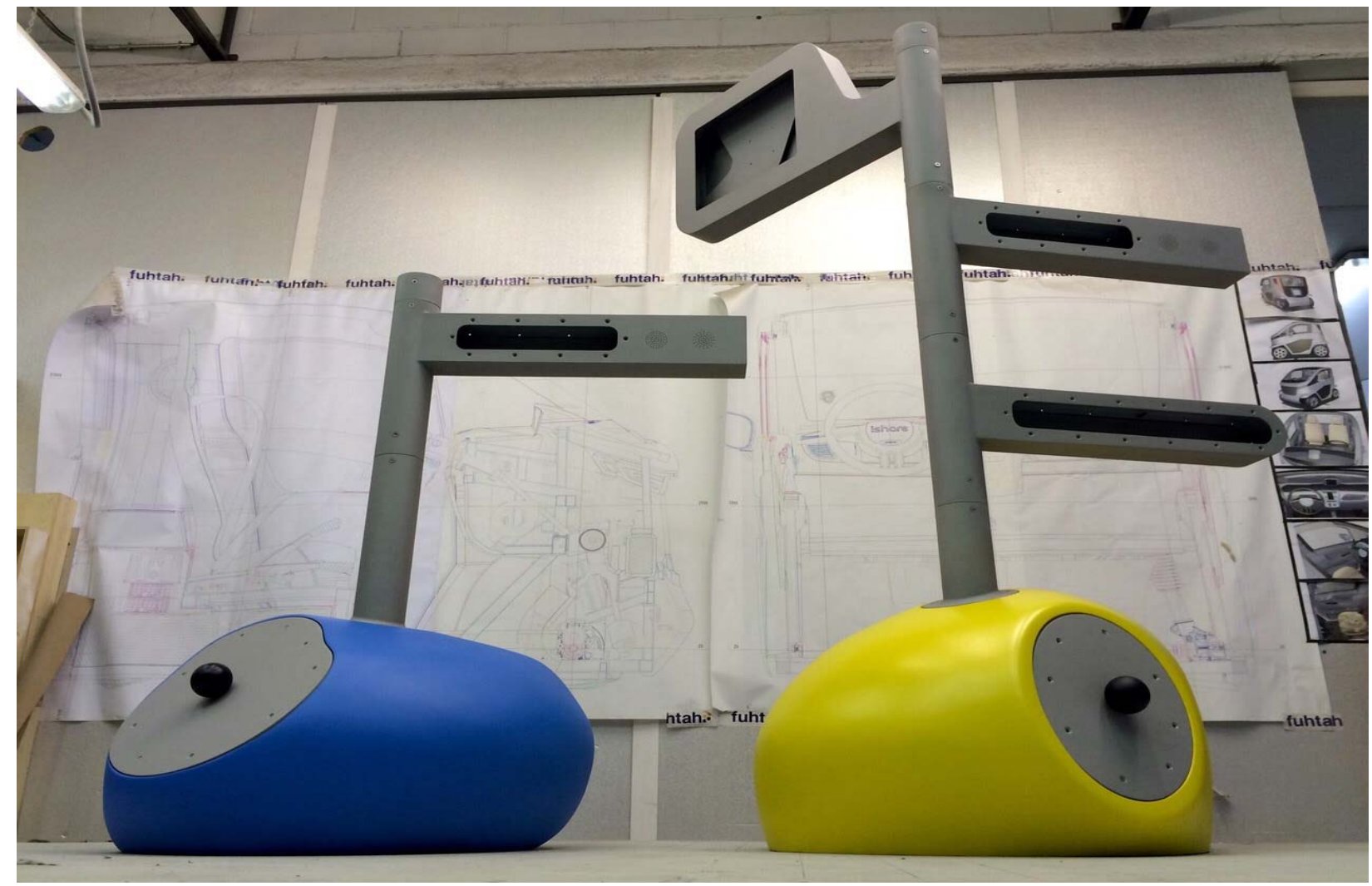

(b)

Fig. 8 Manufacturing of the Birloki system prototype: (a) steel; (b) fiberglass.

Strategically, in this case, the approach of the project will be done from the touristic point of view, focusing mainly on the visitors to the city but not forgetting the permanent inhabitants.

Seven main Level 1 elements will be implemented on the six main open spaces of Casco Viejo plus one at the Tourist Information Center located at Plaza Circular. These points will be composed by the base element and some components on top that provide the following features as shown in Fig. 9.

They will host an interactive tactile screen, environmental sensors, sound, iBeacons, and AR (augment reality) detection. There will be an App, downloadable anywhere online or at the Birloki point hotspot itself. A diagram of the network architecture is shown in Fig. 10.

Complementary to this, we are deploying around 10 12 Birloki Level 2 points to be added to the possible routes that the visitor might walk on the Casco Viejo street. These Level 2 points consist of one beacon inserted inside a carcass and stuck to the wall. They will be clearly visible and will push messages to the users, regarding touristic spots, municipal information or retails and bars offers. All thses information data can be updated through a CMS (client management software) and the data can be stored and reused for the improvement of the general system and to optimize the quality of the experience of the visitors.

As seen in Fig. 11, there will be an online platform that will provide real-time information on the parameters of the sensors and the location of the different Birloki points (both Levels 1 and 2).

This platform can be consulted on the Birloki point screens, the Internet and the App. A mood board at each of the points will generate a global mood plan of the city with colors over a map of the Casco Viejo, taking an important spatial on the collection and usage of subjective human parameters related to the urban realm. Fig. 12 illustrates the locations. 


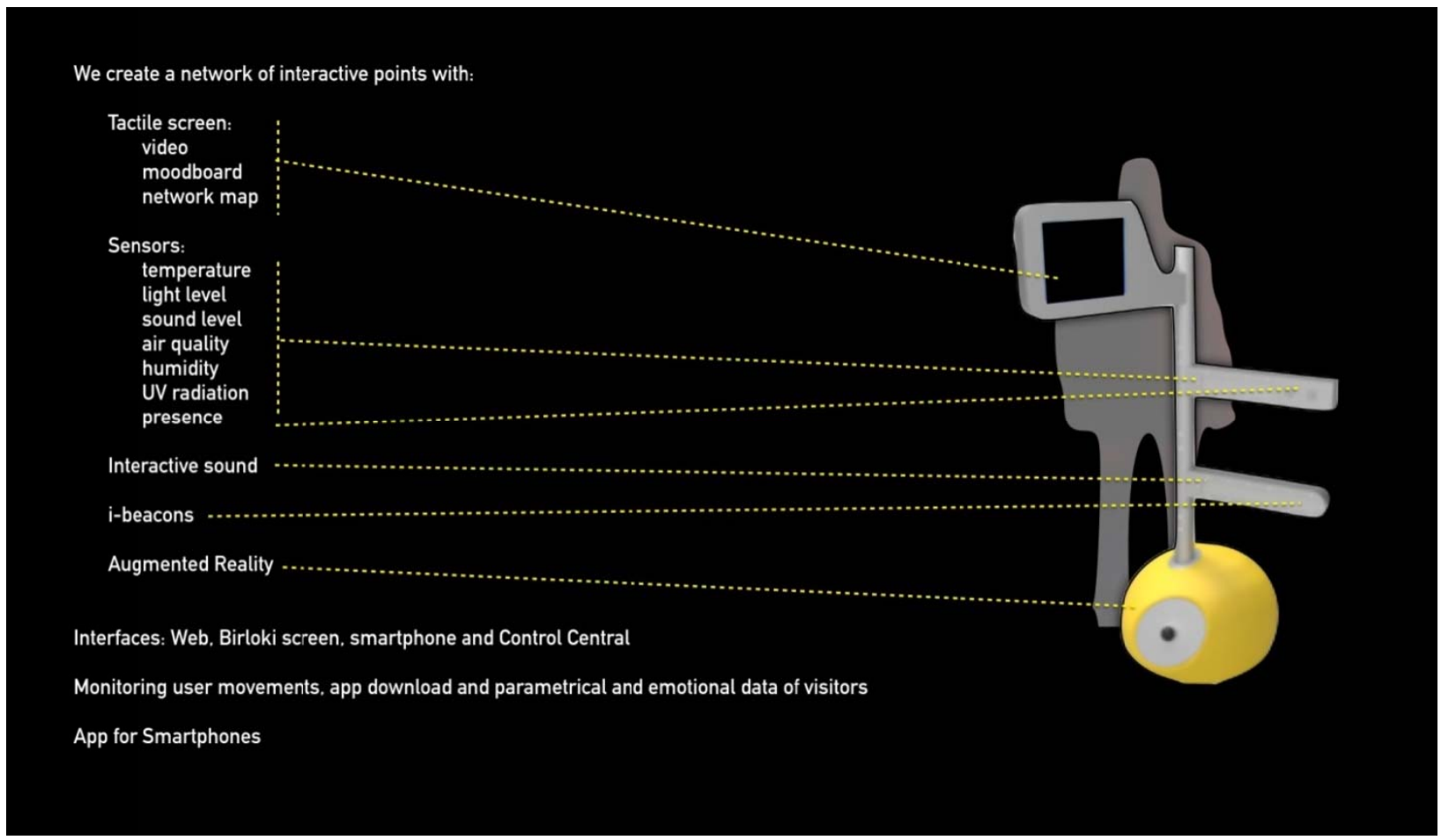

Fig. 9 Birloki system features implemented in the Bilbao testbed.

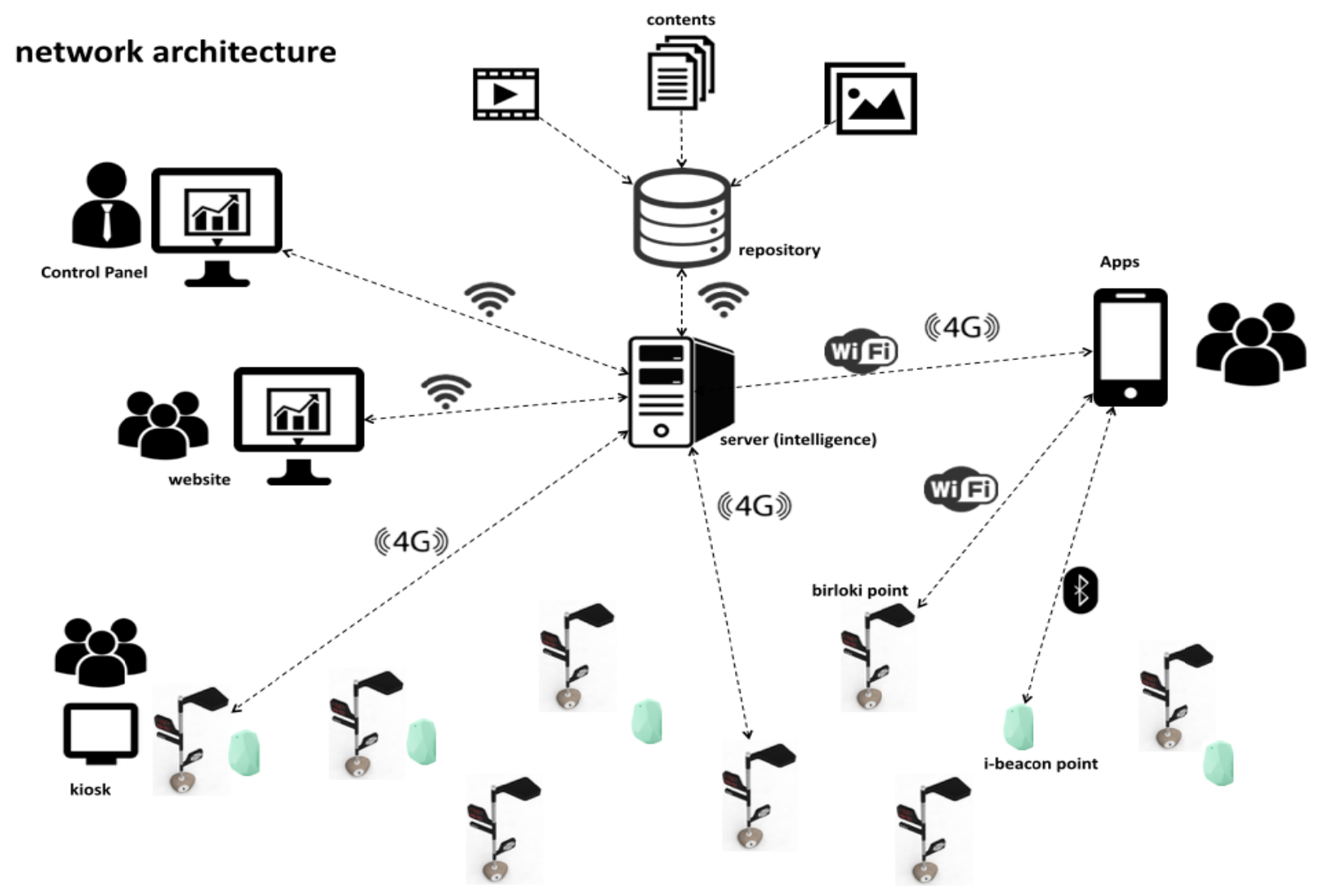

Fig. 10 Network architecture of the Bilbao testbed. 


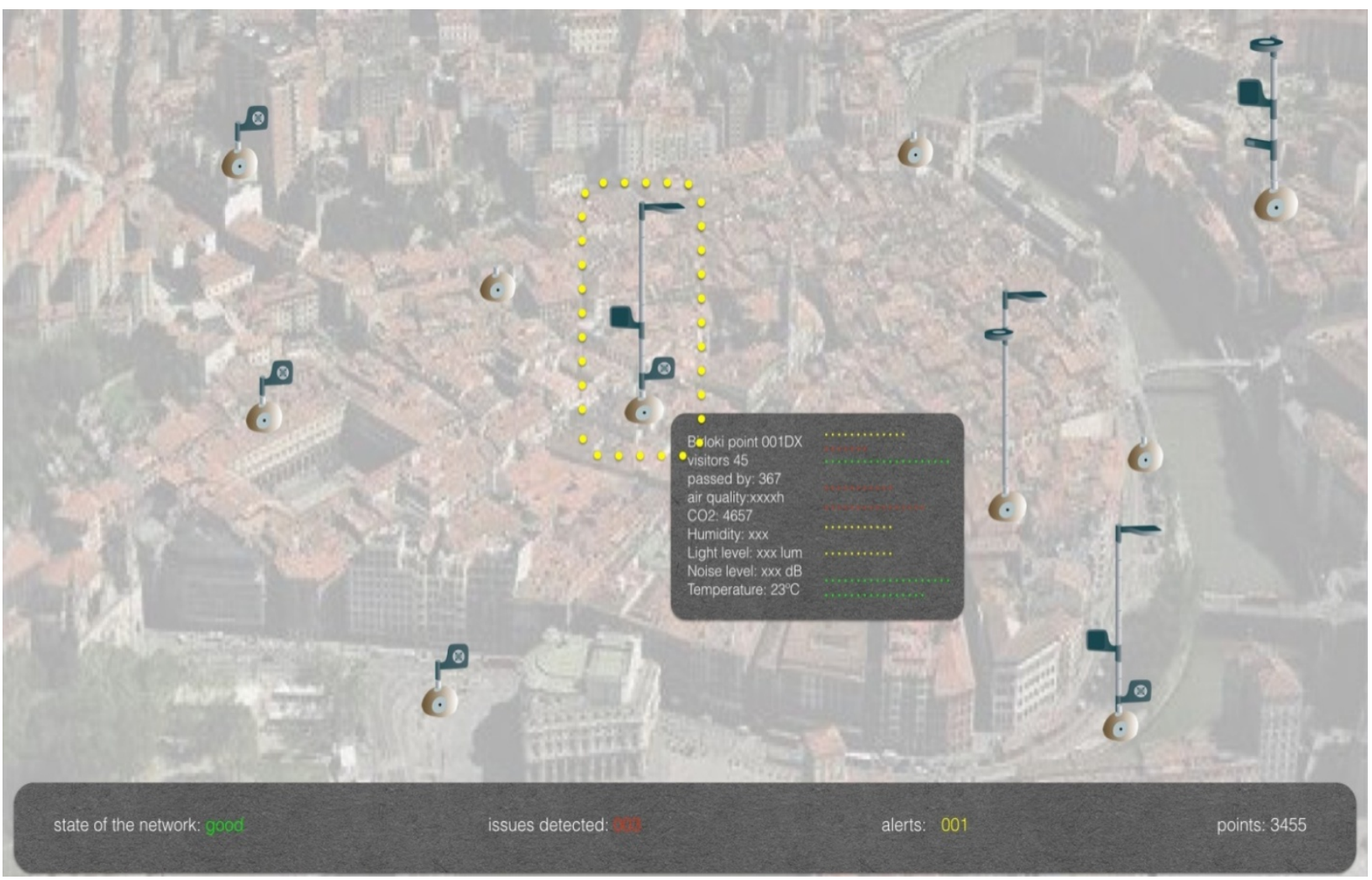

Fig. 11 On line platform for sensors reading.

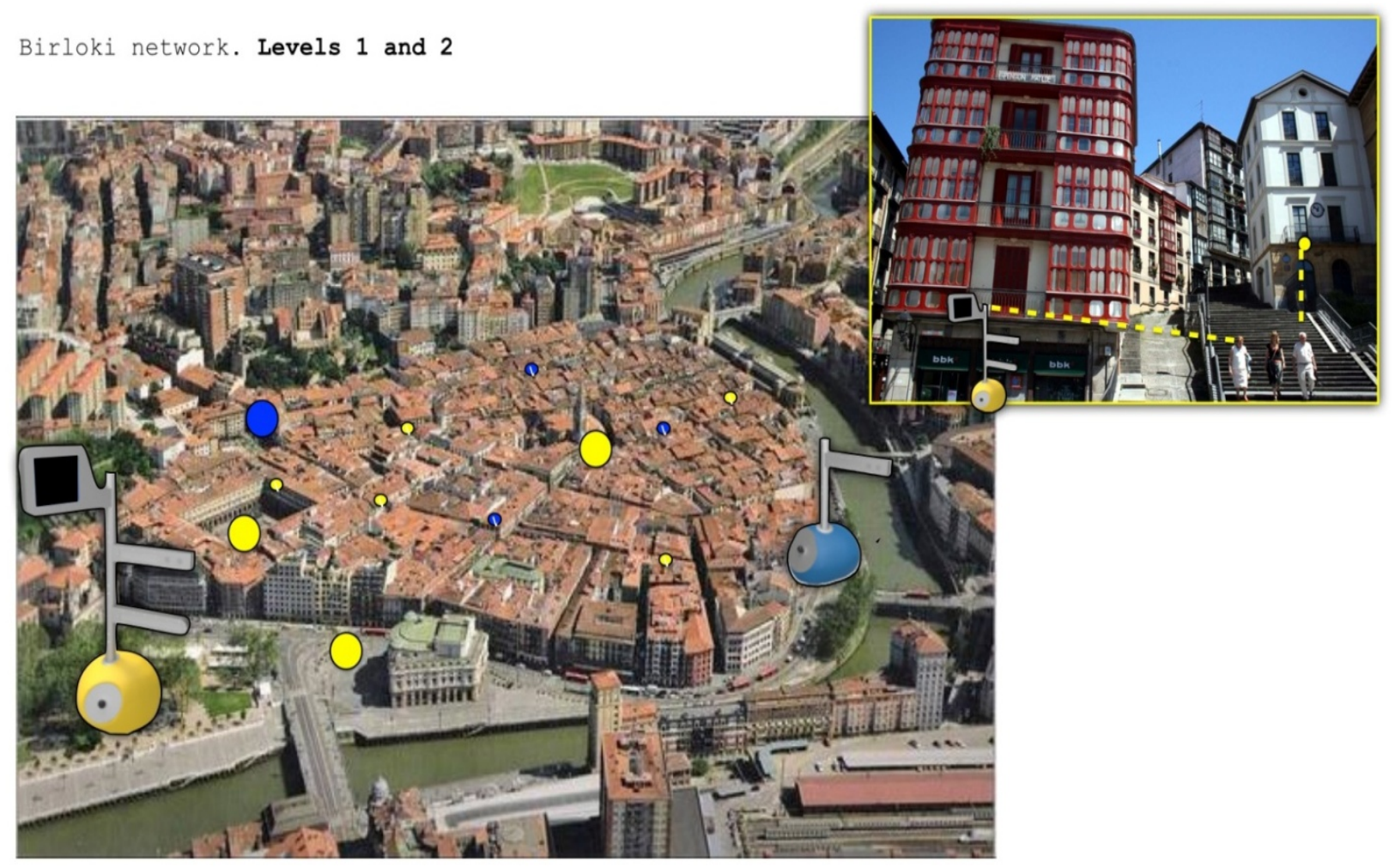

Fig. 12 Locations chosen for the Biloki points in the Bilbao testbed. 


\section{Conclusions}

From a general point of view, one of the most important aspects and conclusions we want to reach in this research is to achieve the establishment of a coherent methodology for urban interactive design. The u-pad method showed as an appropriate theoretical and practical method. And for the validation of data, we establish the following objectives:

- strengthen in a local and international scale the analog and digital identity of the territory;

- make a serios bet on a higher permeability and communicability between the visitors/citizens and the city itself;

- provide better services referred to human mobility, identifying and managing data regarding both objective/functional and emotional/subjective aspects.

As for the collection of data, we are going to work with the following hypothesis that will be monitored, measured and applied a value:

- The implementation of the Birloki network improves the management of people mobility;

- The implementation of the Birloki network improves the interaction between people and the advanced mobility services;

- The implementation of the Birloki network improves the access of people to the retail network and boosts economic activity;

- The implementation of the Birloki network improves the relationship between the persons and the city council;

- The implementation of the Birloki network allows to learn the emotional status of people;
- The implementation of the Birloki network together with the mobility services allows a better understanding of the components and processes that conform the design of advanced services;

- The implementation of the Birloki network allows us to know better the attractive of the points of interest in the Casco Viejo of Bilbao.

\section{References}

[1] MacKinsey Global Institute. 2012. "Urban World: Mapping the Economic Power of Cities." MacKinsey Global Institute. Accessed February 12, 2014. http://www.mckinsey.com/insights/urbanization/urban_w orld.

[2] The World Bank. 2010. "Cities and Climate Change: An Urgent Agenda." The World Bank. Accessed February 12, 2014. http://siteresources.worldbank.org/INTUWM/Reso urces/340232-1205330656272/CitiesandClimateChange.p df.

[3] Euroasiancities. 2015. "Smart Cities Series: Exclusive Q\&A with MIT's Senseable City Lab Director, Prof. Carlo Ratti.” Euroasiancities. Accessed June 14, 2015. http://www.euroasiaindustry.com/article/smart-cities-ser ies-exclusive-q-and-a-with-mits-senseable-city-lab-direct or-prof-carlo-ratti.

[4] Fernandez, M. 2013. "Smart Cities: Research and Civic Engagement in a Networked Society." Presented at the Know Cities 2013 Final Conference, San Sebastián, Spain.

[5] Lerner, J. 2014. Urban Acupuncture. Washington, D. C.: Island Press.

[6] Mehrabian, A. 1996. "Pleasure-Arousal-Dominance: A General Framework for Describing and Measuring Individual Differences in Temperament." Current Psychology 14 (4): 261-92.

[7] Gehl, J. 2010. Cities for People. Washington, D. C.: Island Press.

[8] Nerei. 2015. "Birloki System." Nerei. Accessed July 16, 2015. http://nerei.org/all-service-list/birloki/.

[9] Jacobs, J. 1961. The Death and Life of Great American Cities. New York: Random House. 